\title{
X-ray Mapping Investigations of the Monazites from the Mt Weld Deposit - Compositional Variance as an Indicator of Provenance
}

\author{
T, Murphy ${ }^{1}$, P. Fisher ${ }^{1}$, A. J. Roper ${ }^{1}$, J.K. Reynolds ${ }^{1}$ and R. Wuhrer ${ }^{2}$ \\ ${ }^{1}$ School of Science and Health, University of Western Sydney, NSW 2751, Australia \\ 2 Advanced Materials Characterisation Facility, University of Western Sydney, Australia
}

The Mt Weld lanthanide deposit in central Western Australia is considered to be one of the largest high grade deposits known in the world, first reported as a carbonate and phosphate rich ultramafic silicate intrusion that contained a resource of the Lanthanide series [1]. It has been dated between $1.6-2.0$ billion years, where the formation of a carbonate layer in the cooling melt created a preferred environment for elevated lanthanide deposition [2]. Mineralogical surveys of the area have outlined various primary lanthanide minerals however limited work has been undertaken on the supergene expression of the secondary lanthanide mineralogy, primarily due to the similar physical and electronic nature of the lanthanides.

At Mt Weld, primary and secondary monazites occur; however distinguishing between the two is difficult. The mineral monazite behaves as a lanthanide reservoir and understanding its provenance is of geochemical importance. Monazite is an orthophosphate of the type $\mathrm{A}\left(\mathrm{PO}_{4}\right)$, where $\mathrm{A}=\mathrm{La}-\mathrm{Eu}$. Despite advances in the understanding of monazite growth and stability in high-temperature settings, remarkably little is known about the behaviour of monazite during low-temperature processes. At Mt Weld, monazites exist as an accessory phase associated with a large $\left(15 \mathrm{~km}^{2}\right)$ carbonatite intrusion. With exceedingly low solubilities, monazites are generally considered geologically stable [3]. Subsequent periods of weathering and burial following the carbonatite intrusion have resulted in deeply weathered laterite profiles which still contain appreciable amounts of monazite. The important geochemical question arises as to whether or not the monazite has persisted unaltered over the millions of years since formation.

Understanding monazites geochemical role at Mt Weld is of upmost importance to be able to distinguish between the primary and secondary phases for exploration and mining of the material. Utilising samples from Mt Weld, this study focused on the compositional variance of monazites with respect to calcium content through detailed x-ray mapping (XRM) and x-ray diffraction (XRD) studies. The implications of these studies will aid in increasing understanding on the deposition of lanthanide series elements.

Samples provided were sectioned, mounted and polished according to the standard preparation techniques. Full spectrum quantitative XRM was performed on a JEOL JXA 840 SEM with a Moran Scientific energy dispersive spectroscopy (EDS) Microanalysis system operated at 20kV [4]. A JEOL 8600 EM Probe with a combined EDS and three JEOL wavelength dispersive spectrometers (WDS's) were also used to perform trace and quantitative analysis. The analysis was undertaken at $15 \mathrm{kV}$ and $20 \mathrm{nA}$. Powder XRD analysis and high temperature XRD experiments were performed with a Bruker D8 Advanced Power Diffractometer. The X-ray source was a $\mathrm{Cu} \mathrm{K \alpha}(\lambda 1.5406 \AA)$ operated at $40 \mathrm{kV}$, current of $40 \mathrm{~mA}$ and a step size of 0.02 degrees.

This study has developed an understanding of the supergene expression of the lanthanides from the Mt Weld deposit and reports evidence to illustrate the occurrence of an igneous monazite, $(\mathrm{Ca}, \mathrm{Ln}) \mathrm{PO} 4$, 
exhibiting a calcium substitution of up to $6 \%$. Subsequent secondary mineralisation due to weathering appears to have produced calcium-free monazite in the immediate vicinity of the primary phases.

The inclusion or exclusion of calcium in monazitesXRM results were coupled with the results from the high temperature XRD experiments. This work found that monazite is unlikely to incorporate calcium at temperatures below $873 \mathrm{~K}$. It is therefore possible to classify the monazites at Mt Weld as primary and secondary. Results from SEM analysis of whole rock samples show the proximity and relation between the monazites that have greater calcium content (carbonatite formed), and the secondary monazites which formed in the billions of years post-igneous intrusion. These results indicate (Figure 1) that the monazites found so far at Mt Weld can be divided into two groups; 1) those that contain virtually no calcium and 2) those that contain up to a 3:1 ratio of lanthanide to calcium.

\section{Acknowledgements}

The authors would like to thank Lynas Corporation for providing the samples and the Advanced Materials Characterisation Facility at the University of Western Sydney.

\section{References}

[1] J A. Bunting, W. J. E. van de Graaff and M J. Jackson, Palaeodrainages and Cainozoic palaeogeography of the eastern Goldfields, Gibson Desert and Great Victoria Desert. Geological Survey of Western Australia Annual Progress Rep (1973) pp. 45-50.

[2] A. Michard, Lanthanide series Systematics in Hydrothermal Fluids. Geochemical Society and the Meteoritic Society. 53. Published by Elsivier (1989) pp 745-750.

[3] G. C. Willett, R. K. Duncan, and R. A. Rankin, "Geology and economic evaluation of the Mt. Weld carbonatite, Laverton, Western Australia.” Geol Soc Australia Abstract. Vol. 16 (1986) pp. 97-99.

[4] R. Wuhrer, K. Moran, L. Moran, "Characterisation of materials through X-ray mapping." Materials Forum (2006) vol. 30.

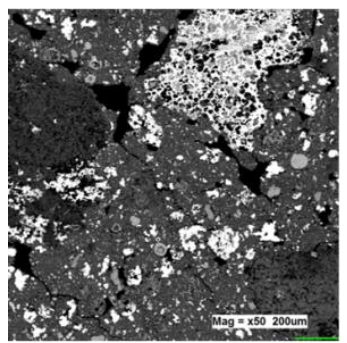

BSE

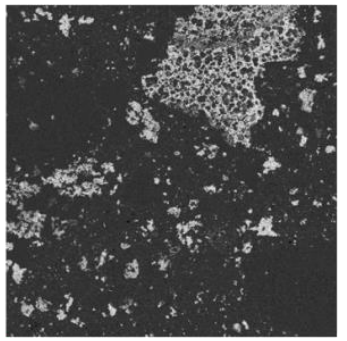

$\mathrm{P}$

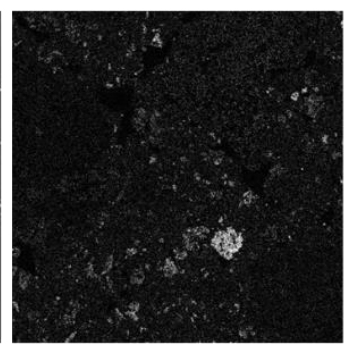

$\mathrm{Ca}$

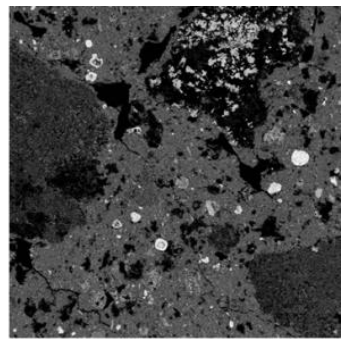

$\mathrm{Fe}$

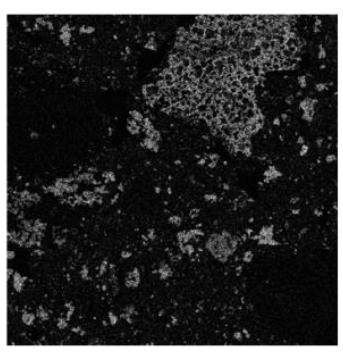

La

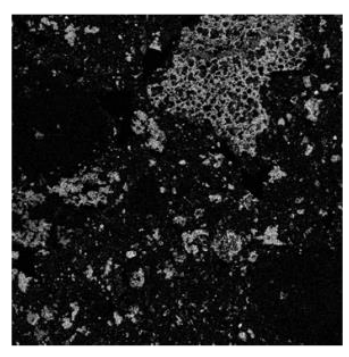

$\mathrm{Ce}$

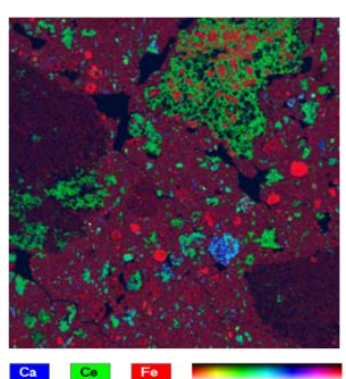

Ca co IFo

Figure 1. BSE image, element maps and a pseudo coloured $\mathrm{Ca}, \mathrm{Ce}$, and $\mathrm{Fe} \mathrm{XRM}$ chemical phase maps (CPM) of Mt Weld monazites, showing distinct chemical composition changes of Cemonazite and Ca-monazite 